\title{
Policy interactions, risk and price formation in carbon markets
}

\author{
William Blyth1, Derek Bunn², Janne Kettunen ${ }^{2}$, Tom Wilson ${ }^{3}$
}

1. Oxford Energy Associates, Wheatley Road, Forest Hill, Oxford OX33 1EH, UK

2. London Business School, Regent's Park, London NW1 4SA, UK

3. Electric Power Research Institute, 3420 Hillview Avenue, Palo Alto, CA 94304-1395 USA

\begin{abstract}
Carbon pricing is an important mechanism for signalling to individuals and companies societal concerns about climate change, and for providing an incentive to invest in carbon abatement. Price formation in carbon markets involves a complex interplay between policy targets, dynamic technology costs, and market rules. Carbon pricing may under-deliver investment due to R\&D externalities and so additional policies may be needed which themselves affect carbon price formation. Also, future abatement costs depend on the extent of technology deployment due to learning-by-doing, leading to some circularity in the analysis of investment, learning, costs and prices. This paper introduces an analytical framework based on marginal abatement cost (MAC) curves with the aim of providing an intuitive (rather than complete) understanding of the key dynamics and risk factors in carbon markets. The framework extends the usual static MAC representation of the market to incorporate policy interactions and some technology cost dynamics. The analysis indicates that supporting large-scale deployment of mature abatement technologies suppresses the marginal cost of abatement, sometimes to zero, whilst increasing total abatement costs. However, support for early stage R\&D may reduce both total abatement cost and carbon price risk. It is anticipated that the intuitive framework introduced here may help in policy design issues around cost containment measures and other market design options such as banking and borrowing (factors that are not currently incorporated into the model).
\end{abstract}

\section{Introduction}

Addressing the twin challenges of energy security and climate change will require a major shift in investment behaviour in the energy sector over the coming decades (IEA 2003, 2008a). This represents a significant challenge not only because of the scale of the transformation required away from the existing energy infrastructure, but also because this has to be undertaken in the context of substantial additional risks due to policy as well as the enhanced concerns about credit and business performance. The policy-formation risks relate, inter alia, to the rate at which international collective actions can be agreed, as well as uncertainties on a range of related factors such as the baseline rate of growth of unmitigated emissions and the cost and availability of abatement options. Policymakers therefore need to be adaptive to changing circumstances, whilst at the same time trying to 
create conditions in their own jurisdictions for motivating private capital towards low-carbon investment in a period of enhanced concerns about investment risks in general.

Carbon pricing (either through taxes or tradable permits) is seen as a necessary though not sufficient element of the policy package to create suitable investment incentives (Stern 2006), since market externalities mean that carbon pricing on its own may tend to under-deliver investment in research and development of new technologies (Rosendahl 2004). This means that other policy mechanisms are required in addition to pricing mechanisms. However, interactions between these multiple policies can undermine the overall efficiency of climate policy (Sorrell 2003), leading to a number of open questions as to how to design and coordinate multiple climate policies.

Another important factor to address is price risk. Risk is an inevitable consequence of the underlying uncertainties in the economics and science of climate change, and the presence of risk in carbon markets does not equate to a market failure. Nevertheless, risk does affect investment behaviour, and is affected by market design. Policy-makers therefore need to take risk into account when designing carbon markets, and when forming expectations about the extent to which investment decision-makers will respond to carbon market price signals. Likewise, companies will need to understand the key drivers and risk factors when formulating their investment and trading strategies.

Two questions this paper aims to address in particular are:

- What is the impact of policy uncertainty and technology cost uncertainty on price risk in a carbon market?

- How do technology-specific policies interact with carbon price signals?

The first question arises because carbon price risk is an important factor in investment decisionmaking by energy companies. Kiriyama 2004 looks at the effects of carbon price and other uncertainties on the value of nuclear power assets and impacts, and shows that risk raises the financial threshold for investment decisions. Reedman 2006 looks at the effect of uncertainty on the timing of various electricity generation technologies, and found that uptake varied significantly depending on investor's view of the risks. Roques 2006 identifies that the hedging role of nuclear power may affect technology choice under conditions of uncertain gas and carbon prices, whilst Rothwell 2006 identifies a significant risk premium for new investment associated with various uncertainties in the financial case for nuclear power. Blyth 2007 and Yang 2008 identify the effects of carbon price risk on investment decisions, showing that, whilst for baseload plant, fuel price risks are often more significant, that carbon price risks are still significant for the low-carbon technology options. There is also a significant body of more generalised research on how to manage risks in market-based mechanisms for pollution control (for a review see Cropper 1992, also Kling 1997). Some of this research focuses on the choice under uncertainty between price-based instruments (taxes) vs. quantity-based instruments (emissions trading), for example Weitzman 1974, Newell 2003, Krysiak 2008, Mandell 2008. Another focus is on design options for constraining price risk in emissions trading schemes, for example price caps and/or price floors (see for example Pizer 2002, Hepburn 2006). 
Despite a few studies that look empirically at carbon price risks and the efficacy of the price signal based on the operation of the EU-ETS since 2005 (e.g. Ellerman 2007), most research on this theme uses quite a stylised representation of carbon price uncertainty, which limits the practical application of the policy recommendations. In general, models of price risk in the EU carbon market have been developed that focus on the abatement options which are expected to be key drivers of the carbon price. For example Seifert 2008 and Chesney 2008 consider carbon prices to be determined by the marginal cost of switching fuel, and so model variability as a function of gas and coal price variability. In contrast, because current carbon allowances are bankable in the EU-ETS, Lewis 2008 assumes future prices will ultimately be determined by the cost of clean coal technology, and uses discounting to arrive at an estimate of the current value of allowances.

This paper builds on these approaches by including a more complete description of the different abatement technologies within the EU-ETS, and including the impact of technology cost dynamics and policy uncertainty. By taking a more holistic and long-term view of carbon market drivers than previous studies, this paper shows how the structure of the carbon market will change as the energy sector evolves, and suggests that the risk characteristics of the carbon market are dependent on climate policy scenarios. In order to characterise risk it is necessary to account for the range of values for the various drivers in the market, and the influence of each of these drivers on the range carbon prices. The problem therefore lends itself to a dynamic stochastic modelling approach, which we develop below. The model results indicate that a shift from a $20 \%$ EU-wide abatement scenario to a $30 \%$ EU-wide abatement scenario (with a corresponding tightening of the level of the EU-ETS cap) would have a significant effect not only on the expected level of the carbon price, but would also alter the fundamental drivers of the carbon price, since switching from coal to gas would no longer be the dominant marginal abatement technology, breaking the link between gas price and carbon price.

The second question (How do technology-specific policies interact with carbon price signals?) is crucial because of the need to manage interactions between technology-specific policies such as standards and subsidies, with nondiscriminatory market mechanisms, such as cap-and trade. Both types of policy are needed. Clarke 2006 identifies the key mechanisms that drive technological change, notably learning-by-doing, $R \& D$ and spillover effects, and these can have an important effect in reducing the cost of abatement (Baker 2008, Gillingham 2008). It is difficult, however, for carbon prices, which are volatile, to credibly guarantee the high future prices that justify current expenditure on R\&D into new technologies (Helm 2003). In consequence, there is evidence that in the presence of multiple market externalities, multiple policy measures may perform better than single policy measures. Goulder 2000 shows that the presence of induced technological change will reduce the cost of achieving a given environmental outcome. This reduction in costs can be used to justify additional policies to promote knowledge accumulation through R\&D and learning-by-doing. Rosendahl 2004 shows that optimal tax rates should be differentiated to reflect the capacity for learning, and will therefore not necessarily be the same across all sources, contrary to the standard assumption of environmental economics; a result also found in Richels 2008 and Otto 2008. Fischer 2008a finds that technology policy is only effective if there is a significant carbon price signal in place, and shows how different policy instruments perform in terms of the cost of emissions reductions in the presence of $R \& D$ externalities (in particular spillover effects which prevent private companies appropriating all the benefits of R\&D expenditure). They show that an optimal portfolio 
of policies achieves emission reductions at a significantly lower cost than any single policy, although the bulk of the emission reductions occur due to the emissions pricing element of the policy package.

Managing such an optimal portfolio in practice is complicated by interactions between these policies. Introducing financial support in addition to the carbon price signal in order to stimulate uptake of new technologies will tend to suppress the carbon price because it reduces the level of abatement required from emissions sources within the trading scheme. It is therefore possible that policy-making succumbs to a self-fulfilling prophesy whereby carbon markets are deemed to be insufficient on their own, justifying more and more additional policy measures which further undermine the efficacy of the carbon market instrument. A prominent illustration of some of the problems of policy interactions and risk is provided by the EU (European Commission 2008) which includes provisions for strengthening the EU emissions trading scheme (EU-ETS), an ambitious target of $20 \%$ of final energy consumption to come from renewable sources by 2020 , targets for improved energy efficiency, as well as a support package for carbon capture and storage. Because they all tackle emissions from the same key sources, there is significant scope for these wide-ranging and potentially transformative policies to interact in a way which reduces their individual efficacy (Stankeviciute 2008). The direction and magnitude of these interactions is taken into account for example in the EU's energy modelling exercises (EU Commission 2008a), which shows a relatively modest depression in the carbon price resulting from the introduction of the $20 \%$ renewable energy target. However, all these scenario analyses are static, and do not take account of the wide range of uncertainties and path-dependent consequences that drive the carbon price. The results in this paper show that if there is expected to be significant scope for technological learning, supporting early stage technology development can reduce the range of uncertainty in future carbon prices as well as overall abatement costs. On the other hand, supporting large-scale deployment through separate technology policies will tend not only to suppress the mean expected carbon price, but can lead to a significant probability of reducing the carbon price to a very low value. Such an occurrence would tend to widen the price differential between the carbon market and the supplementary support mechanisms. This would lead investors to become more reliant on the continuation of those support mechanisms, with consequently greater market fragmentation and reduced scope for policy integration. .

The authors are aware of a certain circularity in the arguments around price formation, risk, marginal cost, investment levels and learning. For example, all else equal, an increase in the carbon price leads to greater levels of investment, increased technological learning, reduced marginal cost and a reduction in carbon price! Such circularity could formally be resolved in an equilibrium model that fully endogenised these feedback mechanisms. The approach taken in this paper on the other hand takes a partial equilibrium approach which does not endogenise technology costs or abatement quanties, but takes these as exogenous inputs to the model. These limitations mean that the current model output may best be viewed as 'raw' data for input into subsequent analysis, rather than an end in itself.

For example, the current model is designed to look at underlying price drivers and risk factors, not actual carbon price risks per se. Carbon prices in real markets will depend on a number of important additional features of the market such as banking and borrowing of allowances between years, and 
the inclusion of cost containment measures such as price ceilings and floors which are not included in the model. By omitting these policy design features, the model output presented here provides 'raw' data on underlying marginal cost drivers which can inform subsequent analysis on potential price behaviour in markets where these policy design features are included.

It should also be noted that the price risks implied by the current model would need to be fed into a separate investment model to look at the implications for investment risk and technology choice. These risks are not taken into account inside the current model when calculating the marginal cost of abatement of a particular technology, but such feedbacks could in principle be incorporated through iterative model running.

Despite the limitations of partial equilibrium analyses, they do have some advantages in providing transparency and intuition, and the relatively simple structure of this model facilitates a stochastic analysis suitable for investigating risk and uncertainty. Providing this intuition, together with ' $r a w$ ' data on the potential dispersion of marginal costs of abatement for subsequent risk analysis is considered to be the main contribution of this paper.

\section{Conceptual framework}

We start with a graphic illustration to help build the intuition for the approach used in this model. A simple view of carbon price formation is provided by stacking up the abatement options in order of increasing marginal cost to provide the familiar representation of a marginal abatement cost (MAC) curve as shown in Figure 1. The expected carbon price is determined by the marginal cost of the abatement option required to meet the target, as shown by the dotted lines in the figure.

Montgomery 1972 showed that if markets are complete, then this will lead to a least-cost solution to meeting the abatement target. Essentially, doing the cheapest things first is economically efficient if we expect to be richer in the future and therefore have positive discount rates for future expenditure.

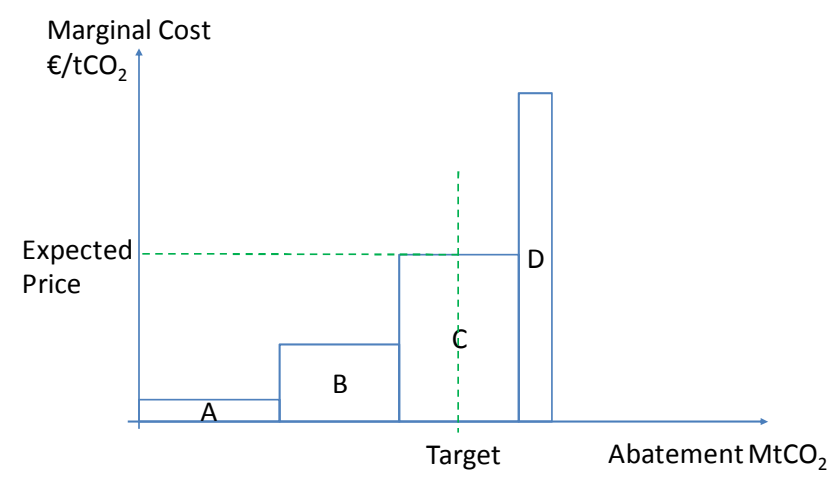

Figure 1. Standard representation of an increasing marginal abatement curve

However, this view does not necessarily address the dynamics of technology development because of other market externalities. We recognise that costs may come down as a result of R\&D expenditure, learning-by-doing, economies of scale and spillovers. This evolutionary learning view 
has precisely the opposite relationship between price and quantity as shown in Figure 2; the cheap abatement options do not become available until they have first been through the more costly stages of research, development and demonstration.

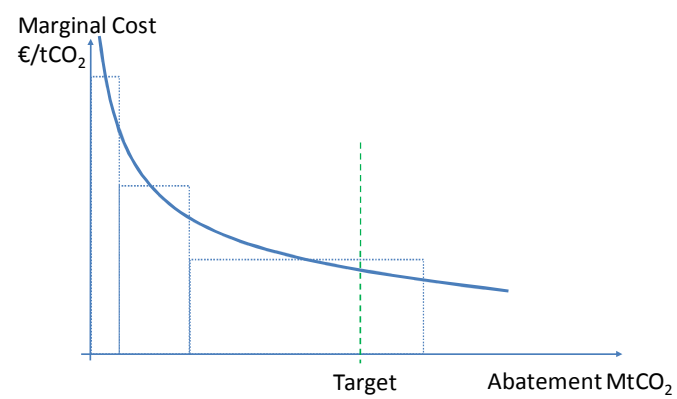

\section{Figure 2. Technology learning proposition for decreasing abatement costs}

In Figure 3 we seek to synthesise these views, whereby, the technologies are still placed in order of ascending cost (as in Figure 1), except in cases where the availability of the technology is dependent on a previous more costly development phase. Thus, the first tranche $D_{1}$ of technology $D$ represents the early deployment version which will be more expensive than subsequent tranches of the same technology $D_{2}$ and $D_{3}$. However, $D_{2}$ and $D_{3}$ are contingent on $D_{1}$ having occurred first. A pure carbon price signal would tend to drive investment up through the ranks of successively more expensive technologies. In this situation, the mature version $D_{3}$ may get 'stuck' behind the development phase of the technology which would not be incentivised until much higher carbon prices were reached. In this situation, abatement option $C$ gets prioritised over option $D_{3}$ despite being more expensive.

Deploying technologies according to the simple increasing marginal abatement function may therefore lead to a sub-optimal economic outcome.

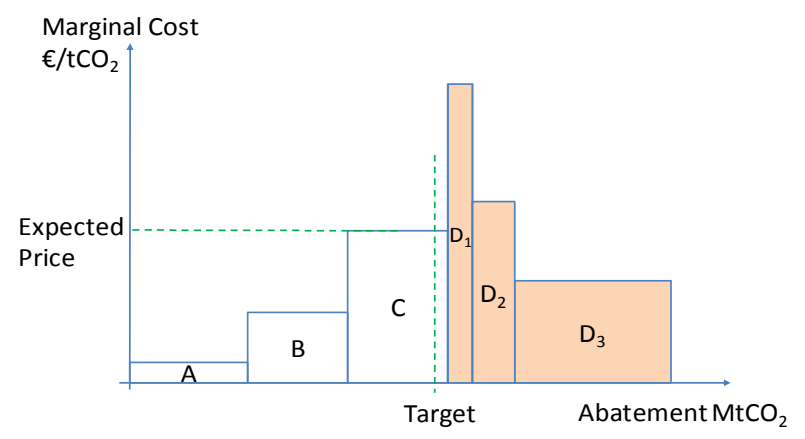

Figure 3. An increasing marginal cost with learning abatement function

The apparently welfare-increasing solution is to bring forward the development phases $D_{1}$ and $D_{2}$ in order to allow the mature technology tranche $D_{3}$ to take its natural place in the ranking (as shown in Figure 4). The cheaper technology $D_{3}$ is now setting the carbon price at a lower level. However, this may, or may not, be efficient. Notice that bringing more expensive technologies to the front of the curve shifts the rest of the curve to the right, effectively displacing cheaper options $A$ and $B$, and suppressing the expected carbon price. The total cost of meeting the target (as measured by the 
area under the curve) may increase or decrease as a result of this shift. The sign and magnitude of the change in abatement cost depends on the additional cost of the initial technology tranches $D_{1}$ and $D_{2}$ relative to the benefits of bringing tranche $D_{3}$ into the curve. This in turn depends on the rate at which costs come down from one tranche to the next. In the classical representation of learning curves, the cost of a technology comes down by a fixed percentage for every doubling of installed capacity (IEA 2000). This representation of learning is similar in that the marginal cost of the second tranche is less than the marginal cost of the first tranche (as a result of learning). In this case, the amount of installed capacity required to achieve the reduction in cost is given by the width of bars $D_{1}$ and $D_{2}$. Figure 4 therefore provides a graphical illustration of the result shown in Rosendahl 2004: supporting technologies with high marginal costs (represented by the height of bars $D_{1}$ and $D_{2}$ ) can be justified as long as the learning rate is fast enough (i.e. bars $D_{1}$ and $D_{2}$ are sufficiently narrow) that the total cost of bringing the technology forward (i.e. the area of bars $D_{1}$ and $D_{2}$ ) is offset by the gains from bringing $D_{3}$ into the curve and displacing the more expensive technology $C$. Conversely, if bars $D_{1}$ and $D_{2}$ turn out to be wider than expected (i.e. slower than expected learning), then the policy measure will turn out to be more costly, and will suppress carbon prices to a greater extent than expected.

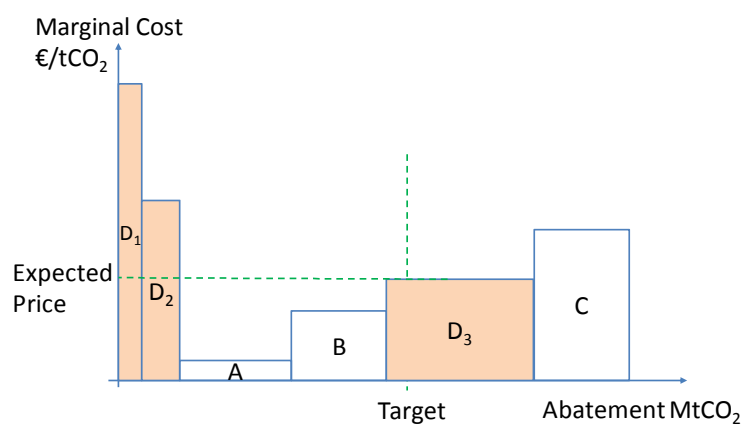

Figure 4. Supporting early technology development allows the mature technology to enter the abatement curve in its natural place

There are many different policy mechanisms available for supporting technology deployment outside of the carbon market. Typically these comprise some form of subsidy targeted at a particular technology or group of technologies with the aim of accelerating their entry into the market. The example that is referred to in this paper is support for renewable electricity, for which there are various types of policy instrument in operation in OECD countries; those that set a fixed price per unit of electricity produced, those that mandate a set quantity of electricity to come from renewable sources, and other types of direct subsidy. In the US, there are various subsidy programmes at the Federal level. These include the production tax credit (PTC) and an investment tax credit (ITC). In addition, 33 US States have enacted legislation to mandate electricity utilities to provide a certain proportion of their electricity from renewable sources. In Europe, two main types of scheme have been implemented; feed-in tariffs and tradable certificate schemes. Feed-in tariffs typically either fix the price per kWh that renewable generators receive for their electricity, or they provide a fixed top-up to the electricity price to bridge the gap between market prices and renewable energy generation costs. In the $\mathrm{EU}$, the two most prominent and successful feed-in tariff systems have been implemented in Germany and Spain (e.g. for a review of the Spanish scheme, see 
del Río González 2008). The UK on the other hand has implemented a tradable certificate scheme in which supply companies are obliged to obtain a certain fraction of their electricity from renewable sources, or else face a penalty 'buy-out' rate for each MWh for which they fall short of the target'.

Although the details of these schemes vary considerably, they all ultimately provide an income stream to the investors that is derived either from the tax-payers, or from electricity consumers. This income is assumed to be distinct from the carbon market in the sense that it is largely unaffected by variations in carbon price. This is a reasonable assumption for feed-in tariff schemes which top-up the market price of electricity, since variations in carbon price will simply be absorbed by variations in the level of this top-up subsidy. It is also a reasonable assumption for the UK tradable certificate scheme, since if carbon prices are low, then the certificate value should increase to compensate, since the total revenue to renewable energy generators is calibrated against the renewables target.

Mechanisms for bringing carbon capture and storage technology through to commercialisation are also likely to rely on subsidies of some form or another. Such policy mechanisms for CCS are much less well established than for renewable energy. The UK government is currently running a competition for companies to bid for public support of a full-scale demonstration plant in the UK, and the EU has stated that aims to support 12 demonstration plant across Europe. The exact form of these subsidies is not yet known. There is some suggestion that revenues from the auctions of allowances from the EU-ETS may be used to fund these demonstrations. One proposed option for subsidising CCS has been to allocate additional allowances (e.g. giving more than one allowances per $\mathrm{tCO}_{2}$ stored).

In practice, there are clearly some linkages between CCS subsidies and the carbon price. Nevertheless, for the purposes of this model, we assume that if governments decide to fund CCS demonstration (i.e. bring it to the front of the curve), then the rate of learning is independent of the carbon price. This is reasonable if we assume that governments consider CCS likely to be essential, and will fund its development irrespective of the price of carbon (in the same way they largely do for renewables).

For the purposes of this model, we therefore make the simplifying assumption for renewables and CCS that 'bringing technologies to the front of the curve' is a policy option available to policymakers, and that the technology developments achieved in this way are independent of the carbon price, and that we do not need to know the details of the subsidy mechanism.

In addition to these policy interaction and learning-by-doing effects, there is also the issue of uncertainty. Both the marginal price and abatement potential for each of the blocks in the curve are stochastic.

This marginal abatement function only provides a partial representation of price formation in carbon markets. For example, the model does not take account of banking of allowances between trading periods, and excludes the feedback between carbon abatement and the price of fuel, due to the reduction in demand. This effect is discussed in Klepper 2006, who illustrates the difficulty of this type of analysis when considering wider equilibrium effects, since the marginal abatement function

\footnotetext{
${ }^{1}$ For an overview of the UK renewable obligation scheme, see:

http://www.berr.gov.uk/whatwedo/energy/sources/renewables/policy/renewables-obligation/page15630.html .
} 
is necessarily a simplified snap-shot of abatement opportunities under very particular assumptions. Another feedback mechanism missing from this approach is the elasticity effect of increased carbon prices (as implied by the marginal cost of meeting the abatement target) on energy demand. Both of these effects are likely to reduce the (marginal and total) costs of meeting the abatement target relative to the results presented in this paper. Inclusion of such feedbacks is left as a topic for further research. Nevertheless, analysis of a stochastic abatement function with discriminatory policy interventions can provide useful insights on the interaction of policies their evolutionary implications.

\section{Specification of a Stochastic Abatement Model}

The model formalises the above conceptual framework, constructing a marginal abatement cost (MAC) function for $N$ abatement options, each option $n$ being represented by a rectangular block to define the MAC. The set of available abatement options $T$ in the model is defined by:

$n \in T, T=\{n 1, n 2, \ldots n x \ldots n N\}$

Each abatement option $n$ is characterised by a marginal cost of abatement $P(n, t)$ and a quantity of abatement $Q(n, t)$ the values of which are specified separately for different time periods $t$. As is commonly the case in MAC curve representations, $P(n)$ is assumed to be independent of $Q(n)$, thus giving the rectangular block shape in the abatement curve. In our case, the model is set up to provide results at 5-year time periods from 2010 to 2030, allowing for the expected technology costs and abatement quantities to evolve over this timeframe. Since marginal costs and abatement quantities for each technology are also stochastic, the quantities and marginal cost values differ for each realisation of the stochastic variables.

The MAC curve is constructed by defining a unique index value for each technology at each time period and each realisation in the Monte Carlo simulation. The index value determines the order of the technologies in the MAC curve, and the set of index values $i$ is given by:

$i \in S, \quad s=\left[i_{n 1}, i_{n 2}, \ldots i_{n x}, \ldots i_{n N}\right]$

The default rule for assigning index values to the technologies is to put lower marginal cost options first, and higher marginal cost options last, such that

$i_{n 1}<i_{n 2}$ if $P(n 1)<P(n 2)$

This ranking is achieved in the Excel model using the Excel-defined RANK function. The price ranking of abatement options is a function of time $i_{n}(t)$ since marginal costs of the options evolve at different rates, and therefore the ordering of technologies in the MAC curve can be different for different time periods. Since technology costs in the model are stochastic, the ordering of technologies (and therefore the ranking index of technologies) may also change in each realisation of the Monte Carlo simulation. 
However, there are some exceptions to this default cost ordering. The first exception is for abatement (or additional emissions) due to the natural variability in electricity demand is always included as the first element in the curve:

$i_{\text {demand variation }}=1 \quad$ for all $t$

Another exception to the default cost ordering arises in the case of immature technologies which require learning-by-doing in order to be available for abatement. In the model, this is assumed to be the case for carbon capture and storage (CCS), where three tranches of technology are represented, tranche 1 (CCS1) being early stage R\&D, tranche 2 (CCS2) being early commercialisation, and tranche 3 (CCS3) being mature technology. Solar energy and offshore wind are each represented with two technology tranches. In these cases, whilst the initial demonstration phase tranches (Solar1 and Offshore Wind1) take their place in the ranking order, subsequent (cheaper) tranches of technology (Solar2 and Offshore Wind2) are constrained to come higher up the cost curve, reversing the normal pricing order, so that for all $t$ :

$$
\begin{aligned}
& \mathrm{i}_{\mathrm{CCS} 1}<\mathrm{i}_{\mathrm{CCS} 2}<\mathrm{i}_{\mathrm{CCS} 3} \\
& i_{\text {solar1 } 1}<i_{\text {Solar2 }} \\
& i_{\text {Offshore wind } 1}<i_{\text {Offshore wind } 2}
\end{aligned}
$$

In the scenarios that simulate the effect of renewable energy policy, an additional constraint is added to this ranking order. Seven technologies representing renewable energy and CCS options are brought to the front of the curve (as illustrated in Figure 4) by explicitly specifying their indexation values such that for all $t$ :

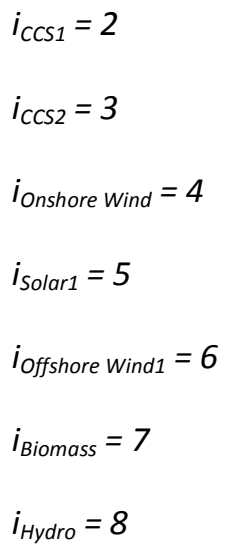

Subsequent technologies are then ranked according to increasing marginal cost, subject to the learning-by-doing constraint mentioned above.

At each $t$, there is an abatement target $A(t)$. This abatement target could also be stochastic, but in our results it is assumed to remain exogenously defined, for each 5-year period. These targets are specified, and are dependent on whether the model is being run under a $20 \%$ or a $30 \%$ EU-wide abatement scenario, the abatement targets for the EU-ETS in 2020 being consistent with the EU Commission's proposals under these respective scenarios. The abatement targets prior to 2020 are 
based on estimates provided by the UK Government Department, BERR, and the annual rate of emission reductions required to meet the 2020 targets are then extrapolated to define a abatement targets between 2020 and 2030. The $30 \%$ EU-wide abatement scenario is therefore assumed to imply a significantly tighter EU-ETS target in all time periods compared to the $20 \%$ EU-wide abatement scenario.

The two main outputs from the model are the marginal cost and total (annual) cost of achieving the abatement target in a particular period. To specify these mathematically, we can define $P(i, t)$ and $Q(i, t)$ as being the marginal cost and abatement quantity provided by the $i^{\text {th }}$ technology in the MAC curve in time period $t$. For any particular time period, the number of options in the MAC curve required to meet the abatement target is $I(t)$ which satisfies the following condition:

$$
\sum_{i(t)=1}^{i(t)} Q(i, t) \geq A(t)
$$

The marginal cost of meeting the target is then generally given by the marginal cost of the $I^{\text {th }}$ abatement option, $P(I, t)$. The exception is in policy cases where the renewable energy and CCS options have been brought to the front of the curve, and where $l<8$. In this case, the abatement target is entirely met by technologies that are financially supported outside of the carbon market. In this case, the marginal cost is recorded as zero to reflect the fact that a carbon price is not required in order to achieve these abatement options. For any particular time period, the total cost of abatement is the area under the MAC function up to the point at which the curve meets the target abatement level:

$\sum_{i(t)=1}^{I(t)-1} P(i, t) \cdot Q(i, t)+\left[A(t)-\sum_{i(t)=1}^{I(t)-1} Q(i, t)\right] \cdot P(I, t)$

This simply amounts to the total cost of abatement for each infra-marginal abatement option plus the cost of the increment of the marginal technology required to meet the abatement target.

A further constraint is placed on the availability of carbon capture and storage (CCS). The mature tranche of the technology is assumed only to be available if the previous 2 tranches have already been implemented (i.e. are fully infra-marginal in the MAC curves) in a previous time period, and if the carbon price has been high enough during that period to equal or exceed the marginal cost of mature phase CCS. Similarly, the intermediate tranche can only be implemented if the first demonstration phase tranche has been implemented in a previous time period. There is therefore a delay of at least 10 years between investment in the first demonstration phase tranche and availability of mature technology CCS. This constraint can be expressed as:

$$
Q(\operatorname{CCS} 3, t)=0 \text { if in period } t-1, i_{C C S 2}>1 \text {, and }
$$




$$
Q(\operatorname{CCS} 2, t)=0 \text { if in period } t-1, i_{C C S 1}>1,
$$

A sensitivity case (labelled CCS+ in the results section) looks at the effect of accelerating CCS development such that the mature phase of CCS is available 5 years (instead of 10 years) after the initial demonstration phase. The assumption is still made that the carbon price needs to be sufficiently high during these 5 years to stimulate commercialisation of the mature phase technology.

The model includes 16 different abatement options, 5 of which are broken down into multiple price tranches giving 22 elements in the curve altogether. For each abatement option and for each 5-year period, the model specifies an expected (mean) value for marginal cost and quantity of abatement, and then defines a separate stochastic process for each of these values. The stochastic processes can be either entirely independent from each other, or can be correlated with other processes in the model. Assumptions about technology cost and abatement potential are derived from the IEA's Energy Technology Perspectives (IEA 2008b) study, together with studies undertaken for the UK government (Redpoint 2007, Poyry 2008).

The abatement options described in the model measure emission reductions relative to a businessas-usual emissions baseline. The baseline used in this case was the baseline scenario for the EU-27 PRIMES model, as published in April 2008 (European Commission 2008a). The model takes account of uncertainty in this baseline by including a contribution of uncertainty as the first element in the cost curve running along the $x$-axis at zero cost. It can contribute either positively to the cost curve, with the effect of pushing the whole MAC function to the right in situations where baseline emissions are lower than expected making achievement of the target easier, or conversely can pull the whole MAC function to the left representing a situation where baseline emissions are higher than expected making achievement of the target more costly.

The PRIMES (op cit) emissions baseline was defined at a disaggregated level to provide emissions levels for both existing plant and new build for each type of generation plant for each 5 -year period to 2030. This disaggregation is important because the different technology options abate emissions from different parts of the baseline emissions. For example, re-ordering the dispatch (i.e. fuel switching) from existing coal plant to existing gas plant only reduces emissions from existing coal plant. As these plants retire over the period to 2030, the potential for abatement from this option diminishes. On the other hand, renewables and nuclear abate emissions by changing the expected mix of new plant, so the expected quantity of abatement $\mathrm{E}[\mathrm{Q}]$ for these options increases over time as the stock of new ${ }^{2}$ plant in the baseline increases over time. Some abatement options are fuelspecific. For example, the following options abate emissions only from new coal build, and therefore also increase in terms of abatement potential over time in line with expected new coal build in the PRIMES baseline:

- building new gas plant instead of new coal plant

- building new integrated gasification and combined cycle (IGCC) plant instead of new coal plant

\footnotetext{
2 'New' plant here refers to plant build any time after the first year of the simulation.
} 
- fitting carbon capture and storage,

A final category of abatement options create emission reductions across the whole EU-ETS, and are therefore subtracted from the total baseline emissions level. This applies to energy efficiency in EUETS sectors, variation in demand for electricity and CDM credits.

Interactions between abatement options are managed within each of these categories in order to avoid double counting emission reductions, and to avoid total abatement opportunities exceeding total available emissions within any particular category. This involved constraining the abatement potential of some of the technologies in order to maintain some diversity of options in the MAC curve. The level of these constraints is defined as a user input, the weakness of this approach being that the constraints are somewhat arbitrary. On the other hand, without these constraints the MAC curve would not reflect the kind of diverse range of abatement options that are likely to be deployed reflecting the more complex drivers of investment decisions that are excluded from this model. For example, the option of building new gas plant instead of new coal plant is restricted to a maximum of $50 \%$ of the baseline new coal build. This reflects (rather simplistically) constraints such as gas availability, price and security of supply that could arise if rates of new gas build were very much higher than expected in the baseline scenario. The sensitivity of the results to this constraint is explored in the results section of this paper.

The model includes several abatement options associated with fuel switching. In each case, the abatement quantity is measured in terms of a reduction relative to the PRIMES baseline scenario.

- An operational switch from existing coal plant to existing gas plant, within the existing generation fleet. The scope for such fuel switching depends on the amount of spare gasfired generation capacity in the system, and the cost of switching depends on the relative efficiencies of the plant. The model calibrates abatement quantity at three different price tranches based on an unpublished study carried out for the UK Department of Business, Enterprise and Regulatory Reform. This study, made available for the current research, shows switching potentials for different carbon price and fuel price assumptions. This type of operational fuel switch is important in the short-term, but becomes less important by 2030 as existing plant is replaced with new plant.

- A shift away from the baseline assumption of investment in new coal or lignite plant to building instead new gas-fired plant. The quantity of such a switch is constrained as described above. The marginal abatement cost in a particular year is derived by calculating the break-even price of carbon required to equalise the long-run marginal cost of electricity generation for gas-fired plant and coal (or lignite) plant. Long-run marginal costs of electricity generation are calculated over the full lifetime of the plant, and discounted back to the year in question. Fuel prices for this calculation are assumed to start at the actual stochastic fuel price for the year in question, escalating at the fuel price escalation rate used in the PRIMES baseline. No feedback between fuel switching levels and fuel prices is included. This option is an important contribution in the medium to long term as this is the timeframe over which there is the opportunity to change investment patterns relative to the baseline. 
- An early replacement of existing coal plant with new gas plant. This option calculates the break-even price of carbon required to equalise the short-run marginal cost of electricity generation from coal plant with the long-run marginal cost of generation from gas plant. This option is only relevant in the short term, and tends to be very expensive, so does not play a significant role in the results.

The stochastic variables in the model are assumed to follow one of the following 3 processes:

A] Time dependent random walk (geometric Brownian motion) where $\sigma$ is the standard deviation of the distribution after one time period, and $Z$ is a function that picks a random number with normal distribution of mean zero and standard deviation of 1 :

$$
x_{j}^{k}=x_{j-1}^{k} \exp \left\{\ln \left(\frac{\varepsilon\left[x_{j}\right]}{E\left[x_{j-1}\right]}\right)-0.5 \sigma^{2}+\sigma Z\right\}
$$

B] Normal distribution about a mean, with no interdependence between time periods, using the same definition for $\sigma$ and $Z$ :

$$
x_{j}^{k}=E\left[x_{j}\right] e^{\sigma z}
$$

C] Uniform distribution between an upper limit of $x_{j}^{\max }$ and a lower limit of $x_{j}^{\min }$, again with no interdependence between time periods, and where $U$ is a function that picks a random number from a uniform distribution between zero to 1 :

$$
x_{j}^{k}=E\left[x_{j}\right]+\left(x_{j}^{\max }-x_{j}^{\min }\right) \mathrm{U}
$$

In some cases, marginal costs and quantities for the abatement options are themselves assumed to directly follow one of the above stochastic processes. In other cases, the costs and quantities are derived indirectly from other stochastic variables. For example, the cost of switching from existing coal plant to existing gas plant is calculated from the operating costs for the two types of plant which depend on stochastic fuel prices. The choice of stochastic process is meant to broadly reflect the type of uncertainty that is faced a priori by a participant in the carbon market. In some cases, these uncertainties relate to the likelihood of future events where there is no historical record from which to carry out detailed econometric analysis. For example, in the case of the quantity of renewable energy in the system, we have assumed a kind of 'absolute' uncertainty (i.e. a uniform probability distribution) within limits that are taken from two different published sets of projections about the amount of each kind of renewable energy that will be installed to satisfy the EU's 2020 target (European Commission 2008a and Powry 2008).

In the case of gas and coal prices on the other hand, there is abundant historical records to draw on. In this paper, we follow the arguments of Pindyck 1999 in assuming that long-run price uncertainty can best be modelled using geometric Brownian motion processes. These simulate price uncertainty but not short-term volatility of prices. Expected values for fuel prices follow the central price scenario used in the PRIMES baseline (Table 1). 


\begin{tabular}{|c|c|c|c|}
\hline \multirow[t]{2}{*}{$\begin{array}{l}\text { Fuel price } \\
\text { baseline } \\
2005 \$ \text { boe }\end{array}$} & & & \\
\hline & Oil & Gas & Coal \\
\hline 2005 & 54.5 & 34.6 & 14.8 \\
\hline 2010 & 54.5 & 41.5 & 13.7 \\
\hline 2015 & 57.9 & 43.4 & 14.3 \\
\hline 2020 & 61.1 & 46 & 14.7 \\
\hline 2025 & 62.3 & 47.2 & 14.8 \\
\hline 2030 & 62.8 & 47.6 & 14.9 \\
\hline
\end{tabular}

Table 1: Fuel Price Scenarios

Standard deviations are calibrated using UK government energy price scenarios, giving values per 5year period of:

$$
\begin{aligned}
& \sigma_{\text {gas price }}=15 \% \\
& \sigma_{\text {coal price }}=7.5 \%
\end{aligned}
$$

Gas and coal price variations are assumed to have a correlation coefficient of $90 \%$. In sensitivity tests, this last assumption on correlation does not have a very strong impact on the results; even with a high degree of correlation the difference in standard deviation for gas and coal price variability means that there will be quite a high degree of variability in the carbon price required to drive fuel switching. Specific assumptions relating to the expected values for the abatement costs and quantities and stochastic processes for each of the abatement options are shown in the Appendix.

The model is run as a Monte Carlo simulation. Each realisation of the stochastic variables produces a different result for the marginal and total cost of meeting the abatement target. The model stores these results and builds up a probability distribution for these marginal and total costs, as presented in the Results section.

\section{Results}

The greatest volume of emission reductions arises from the opportunity of replacing the baseline generation mix with a lower carbon mix of generation plant (since the PRIMES baseline contains a substantial proportion of new coal and gas build ${ }^{3}$ ). Since the replacement of existing plant increases cumulatively over time, the abatement curve tends to be wider in 2030 than in earlier time periods. Together with assumed reductions over time in the cost of several of the abatement options due to spillover and R\&D effects, this means that abatement cost are often only modestly higher in 2030 than in $\mathbf{2 0 2 0}$ despite the significantly greater abatement targets. One of the options included in the model is early retirement of existing coal plant, to be replaced by new gas plant. However, this option is substantially more expensive than switching at the point of new build, and tends not to

\footnotetext{
${ }^{3}$ The PRIMES baseline assumes a continuation of current trends, with a carbon price of around $€ 20 / \mathrm{tCO}_{2}$.
} 
contribute much to the abatement curves. The most significant abatement options in the early time periods tend to be fuel switching to gas from existing coal plant, and CDM credits, whilst the later time period includes a wider range of abatement options as described in the Appendix.

Figure 5 shows the results for a scenario of a 20\% EU-wide abatement target in 2020, with a continuation of the annual rate of emission reduction out to 2030. Table 1 shows the mean values of these distributions, and compares these to the static expectations under a deterministic scenario. The following points can be seen from the results:

a) The base case assumes no additional technology support policies are in place. In this case, the model places the technologies in the abatement curve in order of ascending marginal cost, except where they are contingent on a previous development phase. The total mean annual cost of abatement rises from $€ 19 \mathrm{bn}$ in 2020 to $€ 33 \mathrm{bn}$ in 2030, whilst the mean marginal cost rises from $€ 39 / \mathrm{tCO}_{2}$ to $€ 51 / \mathrm{tCO}_{2}$ over the same period. The spread in the distribution of both marginal and total costs increases considerably for 2030 relative to 2020, and the 2030 distributions tend to be more asymmetric with a longer tail on the right-hand side. The lumpiness of the probability distribution is partly due to the granularity of the abatement curve. For example, the relatively high probability of a marginal price in 2030 of around $€ 20 / \mathrm{tCO}_{2}$ is due to the presence of a significant block in the cost curve at that price relating to nuclear power.

b) To illustrate the effects of policy interaction, this assumes that policies are in place to meet the $20 \%$ renewable energy target in the EU by 2020 with a continuation of these trends following the PRIMES model assumptions out to 2030. Support for CCS tranches 1 and 2 are also assumed to be supported in addition to the carbon market. The effect of this is to bring forward more expensive abatement technologies to the front of the curve making the total cost of meeting the target $€ 42 \mathrm{bn}$ in 2020 and $€ 92 \mathrm{bn}$ in 2030 , significantly more expensive than the basecase. The additional abatement from renewables shifts the rest of the curve to the right. Relative to the basecase, this reduces the marginal cost of meeting the target to $€ 32 / \mathrm{tCO}_{2}$ in 2020 and $€ 23.6 / \mathrm{tCO}_{2}$ in 2030 . The probability distribution for marginal costs has two modes, one around zero, meaning there is a significantly increased chance of carbon prices falling to low values; in this scenario, the probability of the marginal cost dropping to below $€ 10 / \mathrm{tCO}_{2}$ is around $9 \%$ in 2020 and $23 \%$ in 2030 , compared to very low probability in the base case.

c) This impact on carbon prices is even more striking if we take into account the EU's stated target of improving energy efficiency by $20 \%$. The impact on electricity demand of achieving has been estimated on the basis of the European Commissions impact assessment of the Energy Efficiency Action plan. This action plan and the associated energy efficiency target does not have as strong a regulatory status as the renewables target and the EU-ETS, as it lacks a specific directive and binding targets. In order to account for the softer nature of its regulatory status, the delivery of the target is assumed to be uncertain, with an equal probability assumed for any level of efficiency improvement between zero (i.e. business as usual), and full achievement of the $20 \%$ target. The expected level of efficiency improvement under this assumption is therefore half of the stated savings identified in the action plan. Under these assumptions, the expected total costs of meeting the EU-ETS target are $€ 29 \mathrm{bn}$ in 2020 and $€ 50 \mathrm{bn}$ in 2030 . Note that these costs do not take account of the costs of achieving the efficiency improvements which are assumed to 
occur outside of the EU-ETS. It is interesting to note that the stochastic mean total cost is significantly lower than the deterministic expected value. This is because under a deterministic scenario the abatement target is almost entirely met by energy efficiency and renewable energy measures. Under the stochastic scenario, costs are lower because in cases where abatement requirement is greater than expected, low cost measures are available which do not add much to the total cost of abatement, whereas when abatement requirement is less than expected, the amount of renewables required to meet the abatement target is lower, reducing the total costs significantly. The effect on marginal costs of including energy efficiency is dramatic, reducing the expected values to only $€ 3.5 / \mathrm{tCO}_{2}$ in 2020 and $€ 1.5 / \mathrm{tCO}_{2}$ in 2030 . The total costs are also strongly affected, resulting in a probability distribution with two modes, one around zero. This suggests that in some states of the world (corresponding to low economic growth, low energy prices and yet still achieving the $20 \%$ efficiency target), the greenhouse gas target would be met at close to zero cost - i.e. it would be met under business as usual without any additional abatement required.

d) When only the first and second tranches of CCS are brought to the front of the MAC curve, the effect is to slightly increase the total costs of meeting the target, and reduce the marginal costs. There is no significant financial gain to supporting CCS under this scenario since the mature phase of CCS is not required to meet the target in 2030. Similar results are shown for 2030 for the additional sensitivity case is illustrated with the label "CCS+" to denote an accelerated technology development scenario where the mature phase of CCS is available only 5 years after the initial demonstration phase (i.e. assuming CCS1 is implemented in 2015, CCS3 is available from 2020 onwards). Again, in the $20 \%$ abatement scenario, the availability of CCS does not significantly alter the results compared to the basecase. This contrasts with the case of a $30 \%$ EU-wide abatement target where CCS availability affects the results strongly, as described below.

e) Case e) looks at the sensitivity of the cost results to fuel price uncertainty. The results show that removing fuel price uncertainty from the model produces a major reduction in the uncertainty in marginal cost. This is because under deterministic fuel prices and a $20 \% \mathrm{EU}$-wide abatement scenario, fuel switching from coal to gas is very often the marginal abatement option, leading to a much narrower distribution in marginal cost. It should be noted that the actual effect of removing uncertainty in fuel price would have broader consequences than those indicated in this analysis since in reality it would change the economics of individual elements of the costcurve through changes in the risk profile of investments, an effect that is not modelled here. Nevertheless, this sensitivity analysis is a useful indication that fuel price uncertainty is a major source of carbon price uncertainty under this scenario. This contrasts with results in Figure 6e which indicate a different set of price drivers under a $30 \%$ abatement scenario. 
Figure 5. Cost distribution results under a $20 \%$ EU-wide abatement target scenario

a) Basecase no additional technology support policies

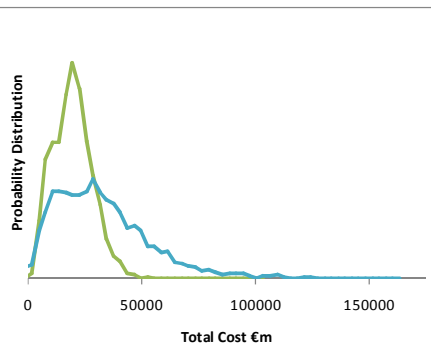

b) Renewable and CCS support

c) Renewable, CCS and energy efficiency
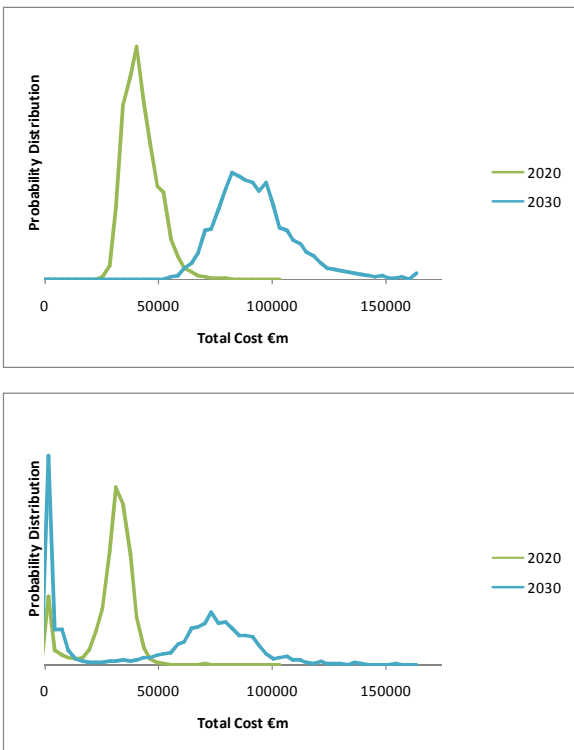

d) CCS only

e) Sensitivity case - zero fuel price volatility
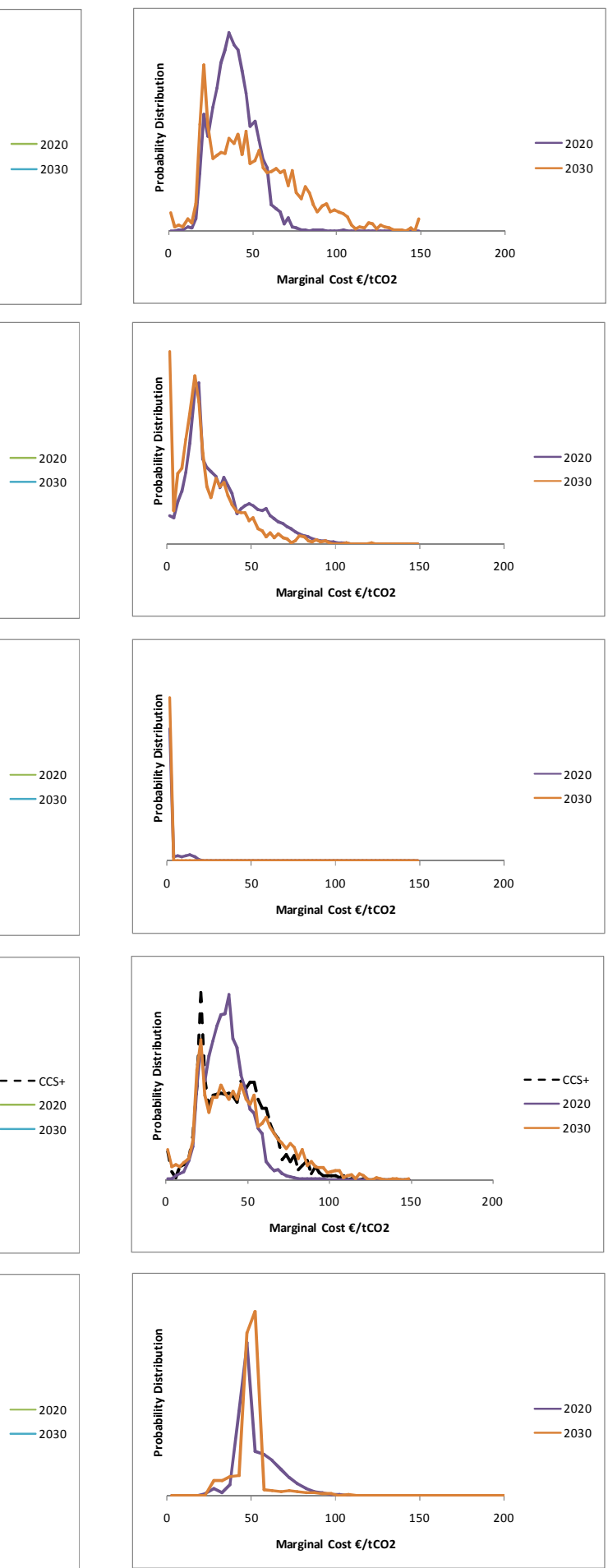
Figure 6 shows the results for a scenario of a 30\% EU-wide abatement target in 2020. Again, it is assumed that there will be a continuation of the emission reduction trends out to 2030, this time at a greater annual rate. Key results are as follows;

a) The basecase again assumes no technology support policies are in place other than the EU-ETS. Total annual costs are $€ 42 \mathrm{bn}$ in 2020 and $€ 78 \mathrm{bn}$ in 2030, significantly higher than the $20 \%$ EUwide abatement scenario. Marginal costs are also significantly higher, at $€ 70 / \mathrm{tCO}_{2}$ in 2020 and $€ 128 / \mathrm{tCO}_{2}$ in 2030 . The expected stochastic marginal cost in 2030 is lower than the static deterministic expectation of $€ 169 / \mathrm{tCO}_{2}$ which is set by offshore wind, again pointing to the fact that a portfolio of options with uncertain costs can lead to a lower overall cost than a deterministic scenario.

b) Under a scenario of policy support for meeting a 20\% renewable energy target in 2020 (with continued trends out to 2030), the total cost of abatement rises to $€ 61 \mathrm{bn}$ in 2020 and $€ 120 \mathrm{bn}$ in 2030. Marginal costs reduce to $€ 51 / \mathrm{tCO}_{2}$ in 2020 and $€ 58 / \mathrm{tCO}_{2}$ in 2030 .

c) Including energy efficiency as well as renewable energy brings the total costs of abatement back to a similar level to the base case. The marginal costs of abatement are again strongly reduced under this scenario, coming down to $€ 28 / \mathrm{tCO}_{2}$ in 2020 and $€ 13 / \mathrm{tCO}_{2}$ in 2030 . In 2030, there is a $44 \%$ chance that the marginal cost of abatement falls below $€ 10 / \mathrm{tCO}_{2}$.

d) When CCS tranches 1 and 2 are brought to the front of the MAC curve, there is a significant reduction in expected marginal costs in 2030 , from $€ 128 / \mathrm{tCO}_{2}$ in the basecase to $€ 90 / \mathrm{tCO}_{2}$ in the CCS case (where technological maturity is reached over 10-years) and $€ 75 / \mathrm{tCO}_{2}$ in the accelerated CCS+ case (where technological maturity is reached in 5 years). The total cost of abatement in 2030 is also reduced, albeit less dramatically from $€ 78 \mathrm{bn}$ in the basecase to $€ 67 \mathrm{bn}$ in the CCS case and $€ 62 \mathrm{bn}$ under the CCS+ scenario. This reduction is because of the availability of the cheaper mature phase CCS technology which under most realisations of stochastic conditions doesn't become available in the basecase. These cost reductions in 2030 would be worth in present value terms today about €3bn for the standard case, and $€ 4 \mathrm{bn}$ for the accelerated development CCS+ case (at 7\% per year). These are rather modest reductions given the overall scale of costs involved. More significant is the considerable shortening of the 'tail' at the upper end of the probability distribution of total cost for the CCS case relative to the basecase, showing that CCS support could lead to a reduction in overall economic risk. This case shows that in contrast to the $20 \%$ abatement scenario, economic benefits of CCS support do become apparent under the $30 \%$ abatement scenario because of the increased level of abatement required and consequent increase in marginal cost of abatement that could be supported. It is expected that the economic benefits would be even greater for deeper cuts and when considering time periods beyond 2030.

e) Under the $30 \%$ EU-wide abatement scenario, switching off the fuel price uncertainty has much less effect on the results than in the $20 \%$ abatement scenario. This is because in this scenario 
fuel switching is almost always inframarginal. Reduced variability in fuel prices therefore reduces the variability of total abatement costs, but makes very little difference to the variability in marginal cost. This is significant from the point of view of understanding carbon-price risks, since it illustrates that the drivers of carbon price variability could be significantly different under a $30 \%$ abatement scenario compared to a $20 \%$ abatement scenario. 
Figure 6. Cost distribution results under a $\mathbf{3 0} \%$ EU-wide abatement target scenario

a) Basecase no additional technology support policies

b) Renewable and CCS support

c) Renewable, CCS and energy efficiency

d) CCS only

e) Sensitivity case-zero fuel price volatility
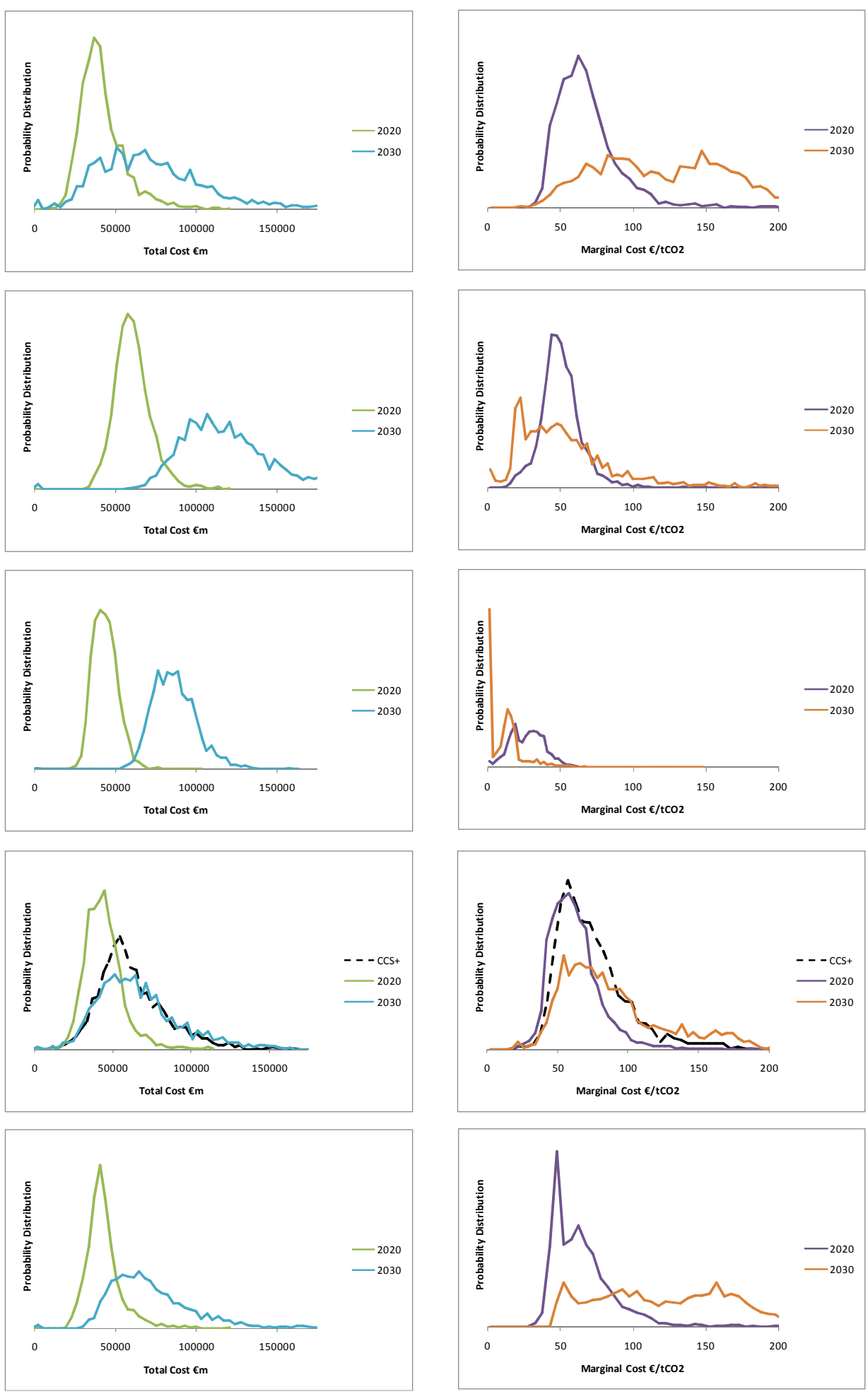
Table 1. Expected values and distributions

\begin{tabular}{|c|c|c|c|c|c|c|c|c|}
\hline \multirow[t]{3}{*}{ Case } & & \multicolumn{3}{|c|}{ Marginal cost results $€ / \mathrm{tCO}_{2}$} & \multicolumn{2}{|c|}{ Total cost $€ m$} & \multirow{2}{*}{$\begin{array}{l}\text { Deterministic } \\
\text { Marginal Cost }\end{array}$} & \multirow{2}{*}{$\begin{array}{c}\text { Deterministic } \\
\text { Total Cost }\end{array}$} \\
\hline & & & Prob & Prob. outside & & Total outside & & \\
\hline & & mean & $<€ 10$ & $\pm 30 \%$ range & Mean & $\pm 30 \%$ range & $€ / \mathrm{tCO} 2$ & $€ \mathrm{~m}$ \\
\hline \multirow[t]{2}{*}{ 5a) $20 \%$ basecase } & 2020 & 39.1 & $0.1 \%$ & $41 \%$ & 19451 & $72 \%$ & 46 & 14223 \\
\hline & 2030 & 50.6 & $1.5 \%$ & $63 \%$ & 32520 & $71 \%$ & 50 & 21860 \\
\hline \multirow[t]{2}{*}{ 5b) $20 \%+R E+C C S$} & 2020 & 32.0 & $9.1 \%$ & $73 \%$ & 42260 & $15 \%$ & 29 & 38331 \\
\hline & 2030 & 23.6 & $22.6 \%$ & $80 \%$ & 92450 & $10 \%$ & 33 & 86408 \\
\hline \multirow[t]{2}{*}{ 5c) $20 \%+R E+C C S+E E$} & 2020 & 3.5 & $88.0 \%$ & $100 \%$ & 28881 & $36 \%$ & 13 & 33448 \\
\hline & 2030 & 1.5 & $98.8 \%$ & $\# N / A$ & 49611 & $92 \%$ & 0 & 81269 \\
\hline \multirow[t]{2}{*}{ 5d) $20 \%+C C S$} & 2020 & 36.6 & $0.5 \%$ & $42 \%$ & 23718 & $59 \%$ & 40 & 18556 \\
\hline & 2030 & 45.0 & $3.4 \%$ & $63 \%$ & 33861 & $60 \%$ & 50 & 24459 \\
\hline Accelerated CCS+ & 2030 & 42.35 & $2 \%$ & $62 \%$ & 32772 & $70 \%$ & & \\
\hline \multirow[t]{2}{*}{ 5e) $20 \%$ deterministic fuel price } & 2020 & 53.2 & $0.1 \%$ & $20 \%$ & 21816 & $35 \%$ & 46 & 14223 \\
\hline & 2030 & 50.5 & $0.0 \%$ & $15 \%$ & 35310 & $46 \%$ & 50 & 21860 \\
\hline \multirow[t]{2}{*}{ 6a) $30 \%$ basecase } & 2020 & 69.8 & $0.0 \%$ & $35 \%$ & 42156 & $30 \%$ & 60 & 34587 \\
\hline & 2030 & 127.7 & $0.1 \%$ & $54 \%$ & 78596 & $57 \%$ & 169 & 50795 \\
\hline \multirow[t]{2}{*}{ 6b) $30 \%+$ RE CCS } & 2020 & 51.0 & $0.1 \%$ & $25 \%$ & 60926 & $11 \%$ & 50 & 55283 \\
\hline & 2030 & 58.1 & $3.5 \%$ & $64 \%$ & 120050 & $20 \%$ & 50 & 102417 \\
\hline \multirow[t]{2}{*}{ 6c) $30 \%+$ RE CCS EE } & 2020 & 27.5 & $6.2 \%$ & $66 \%$ & 43508 & $10 \%$ & 46 & 44497 \\
\hline & 2030 & 13.3 & $44.3 \%$ & $79 \%$ & 86537 & $8 \%$ & 33 & 86716 \\
\hline \multirow[t]{2}{*}{ 6d) $30 \%+\mathrm{CCS}$} & 2020 & 62.4 & $0.0 \%$ & $29 \%$ & 44248 & $27 \%$ & 60 & 37901 \\
\hline & 2030 & 90.0 & $0.0 \%$ & $51 \%$ & 67374 & $43 \%$ & 54 & 45805 \\
\hline Accelerated CCS+ & 2030 & 74.5 & $0.0 \%$ & $32 \%$ & 62256.3 & $36 \%$ & 54 & 45805 \\
\hline \multirow[t]{2}{*}{ 6e) $30 \%$ deterministic fuel price } & 2020 & 66.5 & $0.0 \%$ & $30 \%$ & 42793 & $23 \%$ & 60 & 34587 \\
\hline & 2030 & 126.7 & $0.0 \%$ & $55 \%$ & 76962 & $39 \%$ & 169 & 50795 \\
\hline
\end{tabular}




\section{Sensitivity Analyses for the Base Case}

As for all models, the results are dependent on the assumptions, so a number of model runs were carried out to try to determine some of the key sensitivities, in addition to the test of sensitivity to fuel price variability described in the results above. The parameters tested for sensitivity include;

1. Variability in electricity demand. In this sensitivity test, electricity demand was set to its average value, with no stochastic variation in order to determine the impact on overall cost variability. This sensitivity test shows that the role of variability in electricity demand is fairly modest. As expected, the mean values for total and marginal cost are unaffected by removal of the symmetrical variation in demand. The spread in total cost is reduced by about $15 \%$, and the range for marginal cost is reduced by about $10 \%$ relative to the base case.

2. Variability of the CDM price. In the base case scenario, it is assumed that the price of CDM credits would depend on whether a $20 \%$ or a $30 \%$ EU-wide abatement scenario is being considered. The logic of this is that switch between a $20 \%$ to a $30 \%$ EU-wide abatement target implies a shift towards an international climate policy deal reached under the UNFCCC implying concerted global abatement effort and a significant increase in demand for CDM (or some other equivalent international) credits. In the base case $20 \%$ abatement scenario, CDM credit prices vary between $€ 6-19 / \mathrm{tCO}_{2}$ in 2020, and between $€ 34-134 / \mathrm{tCO}$ in 2030. In the base case $30 \%$ EU-wide abatement scenario, CDM prices range from $€ 19$ $80 / \mathrm{tCO}_{2}$ in 2020 , and $€ 134-210 / \mathrm{tCO}_{2}$ in 2030 . These ranges of prices are taken from results of the GLOCAF model run by the UK Department of Energy and Climate Change. However, a sensitivity variation to this assumption is that the choice between a $20 \%$ or $30 \%$ EU-wide abatement target does not have such a strong causal link to the global demand for and price of $\mathrm{CDM}$ credits. The sensitivity case therefore allows CDM prices to span the full range of variability shown in the GLOCAF results (i.e. $€ 6-80 / \mathrm{tCO}_{2}$ in 2020 , and between $€ 34-210 / \mathrm{tCO}_{2}$ in 2030). This has the effect of increasing the total abatement costs under the $20 \%$ abatement scenario (from €19bn to €31bn in 2020 and from $€ 33 \mathrm{bn}$ to $€ 56 \mathrm{bn}$ in 2030) relative to the base case. Although CDM price under the GLOCAF scenario is higher than the marginal abatement cost under deterministic conditions, under stochastic conditions, CDM becomes inframarginal less often in the sensitivity case, raising the abatement cost compared to the base case. Under the $30 \%$ abatement scenario, costs are reduced because of the cheaper average price of CDM credits in the sensitivity case compared to the $30 \%$ abatement base case. However, the reduction is quite small, with total costs only about $€ 2$ bn lower than the base case.

3. Remove constraints on building new gas-fired generation. One of the limitations of a costcurve model is that it simply chooses the cheapest available option, without taking account of other indirect benefits associated with diversity. In the base case, a fixed constraint is included in the model so that no more than $50 \%$ of the expected new build of coal plant up to the period 2030 can be replaced with new gas plant. To test the sensitivity of the results 
to this assumption, a run was made removing this constraint such that up to $100 \%$ of new coal plant could be replaced by new gas plant if it is cost-effective to do so. This case illustrates an interesting effect associated with technology interactions. Removing the constraint on building of new gas-fired plant instead of new coal-fired plant reduces the expected marginal cost of reaching the abatement target by about $10 \%$. This is not because a move to gas is expected to be cheaper than the alternatives (it is actually the marginal abatement option under expected prices in 2020 under the base case assumptions), but because without the constraint, this option is more likely to be the marginal technology under realisations of the model when the gas price is low implying a lower marginal cost of abatement. However, this benefit does not translate into a reduction in total costs. The mean total cost of abatement is actually higher in Sensitivity Case 4 than under the Base Case. This is because under the model assumptions, an increase in new gas build competes with other new build options, notably IGCC plant, which is cost-effective under 2030 fuel price and technology cost assumptions in the model. Squeezing out IGCC increases total abatement costs by about $5-10 \%$ in this sensitivity case. Clearly, these results on total costs are dependent on model assumptions on how different technology options compete, and a more comprehensive capacity expansion model would probably be needed to investigate such effects in more detail.

\section{Conclusions}

Carbon markets are subject to a number of risks, not least of which is the level of the cap. For example, the EU is committed to a unilateral GHG abatement target of $20 \%$ in 2020 relative to 1990 , increasing to $30 \%$ abatement if other major economies were to take on similar commitments within an international climate agreement (European Council 2007). Achievement of 30\% EU-wide abatement would require a significant ramp-up of abatement effort, including more stringent EUETS caps, and increased levels of international trading (European Commission 2008). At the same time, ambitious targets for renewable energy in the EU will themselves achieve considerable emission reductions, and therefore have important interactions with the carbon market. Previous research on the price behaviour of the EU-ETS has focused on the role of fuel switching between coal and gas, as well as the price profile of international credits, the two key short-term abatement measures available to the market. However, when looking over the longer term, future risk drivers may be quite different from the past. For example, the capacity for fuel switching is largely an inherited feature of the electricity system which may not persist as the electricity system evolves over time in the presence of a carbon price. This paper shows that the marginal technology driving carbon prices in the future is highly dependent on the abatement target and additional technology support mechanisms, which implies that climate policy not only has a direct effect on the expected price, but also strongly affects the risk characteristics of the carbon market.

The model used in this paper is based on a stochastic marginal abatement cost (MAC) function. This structure allows technology cost uncertainty to be modelled in detail. Each abatement option in the MAC has separate assumptions about uncertainty in costs and abatement potential used to drive the stochastic processes. The model also includes uncertainty in the baseline emissions, and uncertainty 
in fuel prices. This model allows the expected cost of each abatement option to evolve in a number of ways. Firstly, expected costs can come down over time (as a result of technological learning through spill-overs or R\&D). Secondly, the cost of some abatement options depends on direct experience of deploying that technology, so that early demonstration plant may be more expensive, and subsequent abatement from that technology is cheaper (i.e. learning-by-doing). Thirdly, some abatement options become more expensive over time due to assumed resource constraints.

The model has been implemented in the context of the $2008 \mathrm{EU}$ climate policy package. Key features of this include: a unilateral EU-wide commitment to achieving $20 \%$ abatement in greenhouse gas emissions to be increased to a $30 \%$ abatement target if other major economies take similar commitments; a directive mandating $20 \%$ of the final energy demand in the EU to come from renewable energy sources; a policy goal of improving energy efficiency by $20 \%$; measures to support early demonstration of carbon capture and storage technology; and strengthening of the EU emissions trading scheme.

The model illustrates the following key results and conclusions:

- Supporting large-scale deployment of renewable energy to meet the EU policy of achieving $20 \%$ renewable energy supply reduces the abatement effort required in the EU-ETS. This significantly reduces the expected marginal cost of abatement, increases the probability of the carbon price dropping close to zero, whilst significantly increasing the overall cost of achieving the abatement target. Introduction of additional energy efficiency measures whilst keeping the EU-ETS target unchanged results in a high probability of a very low carbon price.

- The case for providing support for technology development over and above the carbon price is illustrated by the case of supporting an initial tranche of more expensive demonstration plant for carbon capture and storage (CCS). This can reduce overall abatement costs because it allows the cheaper mature phase of the technology to be introduced at a later date. The total cost reductions are rather modest in 2030 , and are only realised in the more stringent abatement scenario of a 30\% EU-wide abatement target, since the technology is not required before 2030 under the $20 \%$ abatement scenario. The cost reductions beyond 2030 are expected to be greater. They are also sensitive to the assumed rate of technological development; the sooner the cheaper mature phase of the CCS technology becomes available, the greater the cost reductions in 2030 . The results indicate a considerable reduction in marginal abatement cost when CCS is made available through early demonstration of the technology. This result illustrates that it will be important to support technology development in a timely manner depending on the particular technology development pathway in question, and depending on the rate at which convergence between the cost of technology support and carbon prices are expected to occur.

- The model indicates that having a portfolio of different abatement options available can help to reduce the overall abatement cost uncertainty, even when the costs of individual abatement options are highly uncertain. This indicates that making available a reasonably wide range of options from which cost-effective solutions can be chosen could be a useful risk-reduction strategy, and reinforces the benefits of early-stage technology development. 
- Sensitivity analyses indicate that the key drivers of marginal cost (and therefore price risk) in a carbon market depend on what the marginal abatement options are expected to be. So far in the EU-ETS, the carbon price has been driven strongly by gas price variability because fuel switching from coal to gas in surplus capacity has been the marginal abatement option. Under a $20 \%$ EU-wide abatement scenario, gas price variability continues to be a strong driver of variability in the marginal abatement cost. Under a more ambitious $30 \% \mathrm{EU}$-wide abatement scenario, the choice between coal and gas plant is rarely the marginal abatement option, so fuel price variability has little effect on marginal abatement cost variability. This result indicates that climate policy affects not only the expected price, but also the risk characteristics of the carbon market.

- The range of abatement costs in 2030 is considerably wider than in 2020 because of the accumulation of uncertainty over the longer time period for each of the stochastic variables in the model. The lower bounds of the probability distribution of marginal cost tend to be similar for 2020 and 2030, but there tends to be a longer tail towards higher marginal costs in 2030. The fact that uncertainties can accumulate over time needs to be taken into account when considering the length of allocation periods. Previous work by the authors (Blyth et al 2007) indicated that longer allocation periods could reduce the policy risk element of carbon prices. This conclusion needs to be weighed against the importance of other risk factors driving the carbon price, and the potential need for policy to be adaptive to changing circumstances. Further work to enumerate the balance between these various risk factors is required.

- The expected values of marginal and total costs derived from the stochastic model can deviate quite strongly from the deterministic values derived from the static marginal cost curve constructed from the expected marginal costs of each technology. These deviations occur because of the non-linear nature of the cost curve, and illustrate the additional insights that can be gained from taking a stochastic rather than a static analytical approach.

As with any model-based analysis, our representation is not a complete model of carbon pricing, since it excludes banking of permits as well some potentially important feedback mechanisms between carbon abatement, fuel prices and electricity demand. Nevertheless, the results indicate that supporting technology development can potentially disrupt market price signals. Policy formation needs to take account of these effects, and can be informed by the kind of extensive stochastic modelling of path-dependent abatement interactions presented in this paper. 
APPENDIX. Base Case Assumptions for abatement options

\begin{tabular}{|c|c|c|c|c|c|c|}
\hline \multirow[t]{2}{*}{ Technology } & \multicolumn{2}{|c|}{$\begin{array}{l}\text { Expected } \\
\text { Marginal Cost } \\
€ / \mathrm{tCO}_{2}\end{array}$} & \multicolumn{2}{|c|}{$\begin{array}{l}\text { Expected } \\
\text { Abatement } \\
\text { Quantity } \mathrm{MtCO}_{2}\end{array}$} & \multicolumn{2}{|c|}{$\begin{array}{l}\text { Description of Stochastic Process. Values of } \sigma \text { relate to standard deviation per 5- } \\
\text { year period. }\end{array}$} \\
\hline & 2020 & 2030 & 2020 & 2030 & Marginal Cost & Quantity \\
\hline $\begin{array}{l}\text { Variation in power demand, } \\
\text { translated into emissions } \\
\text { uncertainty assuming baseline } \\
\text { average emissions factor. }\end{array}$ & 0 & 0 & 0 & 0 & Not stochastic & $\begin{array}{l}\text { Geometric Brownian motion process for total } \\
\text { power generation, } \sigma=4.5 \%\end{array}$ \\
\hline $\begin{array}{l}\text { Fuel Switching from existing coal } \\
\text { to exising gas (Tranche 1) }\end{array}$ & 20 & 20 & 0 & 0 & \multirow{3}{*}{$\begin{array}{l}\text { Not stochastic. Results are post- } \\
\text { processed to provide a smooth } \\
\text { probability distribution between } \\
\text { the three price tranches. }\end{array}$} & \multirow{3}{*}{$\begin{array}{l}\text { The quantity of abatement available at each } \\
\text { price tranche depends on the relative price of } \\
\text { gas and coal and the economics of switching. } \\
\text { These abatement potentials are calibrated } \\
\text { against model results from BERR showing the } \\
\text { level of fuel switching abatement that occurs } \\
\text { under different price scenarios. }\end{array}$} \\
\hline $\begin{array}{l}\text { Fuel Switching from existing coal } \\
\text { to exising gas (Tranche 2) }\end{array}$ & 40 & 40 & 260 & 210 & & \\
\hline $\begin{array}{l}\text { Fuel Switching from existing coal } \\
\text { to exising gas (Tranche } 3 \text { ) }\end{array}$ & 60 & 60 & 400 & 325 & & \\
\hline $\begin{array}{l}\text { Build new gas instead of new } \\
\text { coal plant. Abatement costs } \\
\text { based on the carbon price } \\
\text { required to equalise the short- } \\
\text { run marginal costs generation } \\
\text { between the two technologies. }\end{array}$ & 46 & 50 & 162 & 307 & $\begin{array}{l}\text { All elements other than fuel prices } \\
\text { in the marginal cost calculation } \\
\text { (capital, O\&M, efficiency, load } \\
\text { factor etc.) are assumed to be } \\
\text { deterministic. }\end{array}$ & Geometric Brownian motion $\sigma=10 \%$ \\
\hline $\begin{array}{l}\text { Build new gas instead of new } \\
\text { lignite plant, calculated as } \\
\text { above. }\end{array}$ & 29 & 33 & 146 & 241 & $\begin{array}{l}\text { Based on short-run marginal costs, } \\
\text { with stochastic fuel prices. }\end{array}$ & Geometric Brownian motion $\sigma=10 \%$ \\
\hline
\end{tabular}




\begin{tabular}{|c|c|c|c|c|c|c|}
\hline \multirow[t]{2}{*}{ Technology } & \multicolumn{2}{|c|}{$\begin{array}{l}\text { Expected } \\
\text { Marginal Cost } \\
€ / \mathrm{tCO}_{2}\end{array}$} & \multicolumn{2}{|c|}{$\begin{array}{l}\text { Expected } \\
\text { Abatement } \\
\text { Quantity } \mathrm{MtCO}_{2}\end{array}$} & \multicolumn{2}{|c|}{$\begin{array}{l}\text { Description of Stochastic Process. Values of } \sigma \text { relate to standard deviation per 5- } \\
\text { year period. }\end{array}$} \\
\hline & 2020 & 2030 & 2020 & 2030 & Marginal Cost & Quantity \\
\hline $\begin{array}{l}\text { Early retirement of coal, replace } \\
\text { with gas. }\end{array}$ & 120 & 123 & 0 & 0 & $\begin{array}{l}\text { Stochastic fuel prices drive cost } \\
\text { variation }\end{array}$ & Geometric Brownian motion $\sigma=2 \%{ }^{4}$ \\
\hline $\begin{array}{l}\text { Energy efficiency in EU-ETS end- } \\
\text { use sectors (Tranche } 1 \text { ) }\end{array}$ & 35 & 35 & 36 & 60 & $\begin{array}{l}\text { Not stochastic. Results are post- } \\
\text { processed to produce a smooth pdf }\end{array}$ & Geometric Brownian motion $\sigma=10 \%$ \\
\hline $\begin{array}{l}\text { Energy efficiency in EU-ETS end- } \\
\text { use sectors (Tranche } 2 \text { ) }\end{array}$ & 75 & 75 & 54 & 89 & based on these two data points. & \\
\hline $\begin{array}{l}\text { CDM credits in a } 20 \% \text { EU-wide } \\
\text { abatement scenario }\end{array}$ & 13 & 84 & $108^{5}$ & 108 & $\begin{array}{l}\text { Normal distribution about a mean. } \\
\sigma \text { calibrated to the Office of Climate } \\
\text { Change GLOCAF model low and } \\
\text { medium price scenarios, varies } \\
\text { between } 30 \% \text { and } 86 \% \text { for different } \\
\text { periods. }\end{array}$ & Geometric Brownian motion $\sigma=10 \%$ \\
\hline $\begin{array}{l}\text { CDM credits in a } 30 \% \text { EU-wide } \\
\text { abatement scenario }\end{array}$ & 50 & 172 & $215^{6}$ & 215 & $\begin{array}{l}\text { Normal distribution about a mean. } \\
\sigma \text { calibrated to the Office of Climate } \\
\text { Change GLOCAF model medium and } \\
\text { high price scenarios. }\end{array}$ & Geometric Brownian motion $\sigma=10 \%$ \\
\hline
\end{tabular}

\footnotetext{
${ }^{4}$ The amount of existing coal available for early retirement has to take account of the retirement schedule (which removes most of the potential by 2030), and the amount of existing capacity that would have already switched to existing gas plant (which removes most of the potential in 2020). Therefore, this option does not contribute much abatement in the current model set up.

${ }^{5}$ Commission proposals to fix volumes at $108 \mathrm{MtCO}_{2}$ per year up to 2020 in a $20 \%$ abatement scenario, and is These annual expected quantities are assumed to continue to 2030.

${ }^{6}$ CDM limits proposed by Commission to be increased by an unspecified amount under a $30 \%$ abatement scenario. The assumption is made here that the volume of credits allowed into the EU-ETS in a $30 \%$ abatement scenario would be doubled relative to the $20 \%$ abatement scenario.
} 


\begin{tabular}{|c|c|c|c|c|c|c|}
\hline \multirow[t]{2}{*}{ Technology } & \multicolumn{2}{|c|}{$\begin{array}{l}\text { Expected } \\
\text { Marginal Cost } \\
€ / \mathrm{tCO}_{2}\end{array}$} & \multicolumn{2}{|c|}{$\begin{array}{l}\text { Expected } \\
\text { Abatement } \\
\text { Quantity } \mathrm{MtCO}_{2}\end{array}$} & \multicolumn{2}{|c|}{$\begin{array}{l}\text { Description of Stochastic Process. Values of } \sigma \text { relate to standard deviation per 5- } \\
\text { year period. }\end{array}$} \\
\hline & 2020 & 2030 & 2020 & 2030 & Marginal Cost & Quantity \\
\hline \begin{tabular}{|l|} 
Build integrated gasification \\
combined cycle (IGCC) coal \\
instead of standard new coal \\
build. Abatement cost based on \\
comparison of long-run marginal \\
costs of power generation.
\end{tabular} & -4 & -20 & 51 & 80 & $\begin{array}{l}\text { Variation on costs only arises from } \\
\text { fuel price variation. Technology cost } \\
\text { uncertainty is not included in the } \\
\text { model. }\end{array}$ & $\begin{array}{l}\text { The quantity of IGCC constrained to } 30 \% \text { of the } \\
\text { new coal build capacity in PRIMES baseline. } \\
\text { Geometric Brownian motion } \sigma=5 \%\end{array}$ \\
\hline $\begin{array}{l}\text { CCS (1 }{ }^{\text {st }} \text { Tranche), demonstration } \\
\text { plant }\end{array}$ & 175 & $135^{7}$ & $20^{8}$ & 20 & $\begin{array}{l}\text { Normal distribution around these } \\
\text { expected costs } \sigma=30 \% \text {, with } 75 \% \\
\text { correlation with CCS } 2 \& 3 \text {. }\end{array}$ & $\begin{array}{l}\text { Quantity in } 2020 \text { assumed to vary with normal } \\
\text { distribution, } \sigma=20 \% \text {. Quantity after } 2020 \\
\text { remains constant. }\end{array}$ \\
\hline $\begin{array}{l}\text { CCS ( } 2^{\text {nd }} \text { Tranche), early } \\
\text { commercialisation }\end{array}$ & 87 & 72 & $39^{9}$ & $39^{10}$ & $\begin{array}{l}\text { Normal distribution around these } \\
\text { expected costs } \sigma=30 \% \text {, with } 75 \% \\
\text { correlation with CCS } 1 \& 3 \text {. }\end{array}$ & $\begin{array}{l}\text { Quantity in } 2020 \text { assumed to vary with normal } \\
\text { distribution, } \sigma=20 \% \text {. Quantity after } 2020 \\
\text { remains constant. }\end{array}$ \\
\hline $\operatorname{CCS}\left(3^{\text {rd }}\right.$ Tranche), mature & 58 & 54 & 26 & $296^{11}$ & atement costs calculated on basis & Geometric Brownian motion $\sigma=10 \%$ \\
\hline
\end{tabular}

${ }^{7}$ The costs are assumed to come down over time due to spillover learning and/or R\&D. Expected costs of the mature phase are based on estimates from EPRI and IPCC reports. Costs of the first development phase are based on a multiple of the mature phase technology costs.

${ }^{8}$ The quantity of abatement from Tranche $1 \mathrm{CCS}$ is based on 12 demonstration plant in the EU of 300MW each.

${ }^{9}$ The quantity for Tranche 2 is assumed to be double that of Tranche 1, representing a intermediate stage of development.

${ }^{10} \mathrm{CCS} 2^{\text {nd }}$ Tranche is assumed to be available only if $\operatorname{CCS} 1^{\text {st }}$ tranche is implemented at least 1 period (i.e. 5 years) prior to the time period being considered. Similar considerations apply for Tranche 3.

${ }^{11}$ The abatement potential in 2030 for the mature phase Tranche 3 is calibrated against the figure in ETP study under the ACT scenario, namely that $24 \%$ of total power generation could come from coal plant with CCS. 


\begin{tabular}{|c|c|c|c|c|c|c|}
\hline \multirow[t]{2}{*}{ Technology } & \multicolumn{2}{|c|}{$\begin{array}{l}\text { Expected } \\
\text { Marginal Cost } \\
€ / \mathrm{tCO}_{2}\end{array}$} & \multicolumn{2}{|c|}{$\begin{array}{l}\text { Expected } \\
\text { Abatement } \\
\text { Quantity } \mathrm{MtCO}_{2}\end{array}$} & \multicolumn{2}{|c|}{$\begin{array}{l}\text { Description of Stochastic Process. Values of } \sigma \text { relate to standard deviation per } 5- \\
\text { year period. }\end{array}$} \\
\hline & 2020 & 2030 & 2020 & 2030 & Marginal Cost & Quantity \\
\hline technology & & & & & $\begin{array}{l}\text { of a cashflow calculation. Capital } \\
\text { costs for CCS vary with a normal } \\
\text { distribution } \sigma=30 \% \text {. Also accounts } \\
\text { for fuel price variation. }\end{array}$ & \\
\hline Onshore Wind ${ }^{12}$ & 106 & 94 & $16^{13}$ & $40^{14}$ & $\begin{array}{l}\text { Geometric Brownian motion } \\
\text { process } \sigma=5 \%\end{array}$ & $\begin{array}{l}\text { Uniform probability distribution for generation } \\
\text { between minimum of 26TWh (based on PRIMES } \\
20 \% \text { renewables scenario), and maximum of } \\
\text { 34TWh based on BERR estimate in } 2020 \text {. }\end{array}$ \\
\hline Offshore Wind & 185 & 167 & 41 & 105 & $\begin{array}{l}\text { Geometric Brownian motion } \\
\text { process } \sigma=5 \%\end{array}$ & $\begin{array}{l}\text { Uniform probability distribution for generation } \\
\text { between minimum of 69TWh, and maximum of } \\
\text { 88TWh in } 2020 \text {. }\end{array}$ \\
\hline Solar 1 & 2600 & 2300 & 3 & 17 & $\begin{array}{l}\text { Geometric Brownian motion } \\
\text { process } \sigma=10 \%\end{array}$ & $\begin{array}{l}\text { Uniform probability distribution for generation } \\
\text { between minimum of 5TWh, and maximum of } \\
\text { 7TWh in } 2020 \text {. }\end{array}$ \\
\hline Nuclear & 16 & $16^{15}$ & 78 & $183^{16}$ & Deviations are due to coal price & Geometric Brownian motion process $\sigma=5 \%$ \\
\hline
\end{tabular}

${ }^{12}$ Figures for the mean costs for all renewable technologies are based on figures provided by BERR.

${ }^{13}$ Mean quantity figures are based on the level required to meet the EU's 2020 target of $20 \%$ renewable energy supply. This is extrapolated to 2030 following the figures in the relevant PRIMES scenario.

${ }^{14}$ Figures for 2030 are based on trends in the PRIMES renewables scenario for all renewables. 


\begin{tabular}{|l|l|l|l|l|l|l|}
\hline Technology & \multicolumn{2}{|l|}{$\begin{array}{l}\text { Expected } \\
\text { Marginal Cost } \\
\epsilon / \mathrm{tCO}_{2}\end{array}$} & $\begin{array}{l}\text { Expected } \\
\text { Abatement } \\
\text { Quantity } \mathrm{MtCO}_{2}\end{array}$ & $\begin{array}{l}\text { Description of Stochastic Process. Values of } \sigma \text { relate to standard deviation per 5- } \\
\text { year period. }\end{array}$ \\
\hline & 2020 & 2030 & 2020 & 2030 & Marginal Cost & Quantity \\
\hline Biomass & $76^{17}$ & 74 & 106 & 203 & $\begin{array}{l}\text { Biomass fuel prices, have a normal } \\
\text { distribution around the mean with } \\
\sigma=15 \%\end{array}$ & $\begin{array}{l}\text { Uniform probability distribution for generation } \\
\text { between minimum of 177TWh, and maximum } \\
\text { of 226TWh in 2020. }\end{array}$ \\
\hline New hydro & $20^{18}$ & 20 & 7 & 1 & $\begin{array}{l}\text { Geometric Brownian motion } \\
\text { process } \sigma=5 \%\end{array}$ & $\begin{array}{l}\text { Uniform probability distribution for generation } \\
\text { between minimum of 12TWh, and maximum of } \\
16 T W h \text { in 2020. }\end{array}$ \\
\hline
\end{tabular}

\footnotetext{
${ }^{15}$ Marginal costs based on BERR study.

${ }^{16}$ Potential for additional nuclear build is calibrated against the ETP scenario, taking the difference between the BLUE scenario and the baseline, and assuming this additional $12 \%$ of generation capacity from nuclear could be phased in by 2030 .

${ }^{17}$ Marginal costs based on a BERR study.

${ }^{18}$ Marginal costs based on a BERR study
} 


\section{References}

Baker, E. Clarke, L. Shittu, E. (2008) "Technical change and the marginal cost of abatement" Energy Economics, 30 (6) 2799-2816

Blyth, W. Bradley, R. Bunn, D. Clarke, C. Wilson, T. Yang, M. (2007) "Investment risks under uncertainty" Energy Policy 35, 5766-5773

Chesney, M. Taschini, L. (2008) "The Endogenous Price Dynamics of Emission Allowances: An Application to CO2 Option Pricing" Swiss Finance Institute Research Paper Series N08 - 02

Clarke, L. Weyant, J. (2006) "On the sources of technological change: Assessing the evidence", Energy Economics Vol 28 Issues 5-6 p579-595

Criqui, P., Mima, S., Viguir, L., (1999) "Marginal abatement cost of CO2emission reductions, geographical flexibility and concrete ceilings: an assessment using the POLES model" Energy Policy $27,585-601$

Cropper, M. and W.O. Oates, (1992) "Environmental economics: a survey" Journal of Economic Literature, 675-740

del Río González, P. (2008). "Ten years of renewable electricity policies in Spain: An analysis of successive feed-in tariff reforms" Energy Policy (36:8) pp2907-2919

Denton, M., A. Palmer, A. Masiello, P. Skantze. (2003) "Managing market risk in energy" IEEE Transactions on Power Systems 18 494-502.

DTI (2007) "Meeting the Energy Challenge; a White Paper on Energy" Department of Trade and Industry, London May 2007.

Dixit, A. K. Pindyck, R. S. (1994) "Investment under Uncertainty" Princeton University Press, ISBN 0691-03410-9

Ellerman D. and Buchner, B. (2007) "The European Union Emissions Trading Scheme: Origins, Allocation, and Early Results" Review of Environmental Economics and Policy 1(1):66-87

Ellerman, D.A., Decaux, A., (1998) "Analysis of Post-Kyoto CO2 Emission Trading Using Marginal Abatement Curves" Report 40, Massachusetts Institute of Technology, Joint Program on the Science and Policy of Global Change

European Commission (2008) "20 20 by 2020: Europe's climate change opportunity" Communication from the Commission COM(2008)30

European Commission (2008a) "European Energy and Transport; Trends to 2030 - 2007 Update" Belgium: European Commission Directorate General for Energy and Transport 
European Council (2007) Presidency Conclusions of the Brussels European Council (8/9 March 2007) 7224/1/07 Rev 1.

Froot, K. A., D. S. Scharfstein, J. C. Stein. (1993) "Risk management: Coordinating corporate investment and Financing policies." The Journal of Finance 48(5) 1629-1658.

Fischer, C. (2008a) "Emissions pricing, spillovers, and public investment in environmentally friendly technologies" Energy Economics 30 (2) 487-502

Fischer, C. Newell, R. (2008b) "Environmental and technology policies for climate mitigation" Journal of Environmental Economics and Management 55 142-162

Gillingham, K. Newell, R. Pizer, W. (2008) "Modelling endogenous technological change for climate policy analysis" Energy Economics 30 (6) 2734-2753

Goulder, L. Mathai, K. (2000) "Optimal $\mathrm{CO}_{2}$ abatement in the presence of induced technological change" Journal of Environmental Economics and Management 39 1-38

Helm, D., Hepburn, C., Mash, R. (2003) "Credible carbon policy" Oxford Review of Economic Policy 19 (3), pp. $438-450$

Hepburn, C. et. al. (2006) “Auctioning of EU ETS phase II allowances: how and why?" Climate Policy 6 p137-160

IEA (2000) "Experience Curves for Energy Technology Policy", OECD/IEA, Paris

IEA (2003) World Energy Investment Outlook. Paris : International Energy Agency, 2003.

IEA (2007) “Climate Policy Uncertainty and Investment Risk" Paris ISBN 978-92-64-03014-5

IEA (2008a) World Energy Outlook. Paris: International Energy Agency, 2008

IEA (2008b) Energy Technology Perspectives: Paris: International Energy Agency, 2008

Kettunen, J. Bunn, D. Blyth, W. (2008) “Corporate Investment Behaviour under Climate Change

Policy Risk" Operations Research, submitted Aug 2008.

Kiriyama, E., and A. Suzuki (2004): "Use of Real Options in Nuclear Power Plant Valuation in the Presence of Uncertainty with CO2 Emission Credit," Journal of Nuclear Science and Technology, 41(7), 756-764.

Klepper, G. Peterson, S. (2006) "Marginal abatement cost curves in general equilibrium: The influence of world energy prices" Resource and Energy Economics, 28 (1) 1-23

Kling, C. Rubin, J. (1997) "Bankable permits for the control of environmental pollution" Journal of Public Economics 64 101-115

Krysiak, F. (2008) "Prices vs. quantities: The effects on technology choice" Journal of Public Economics 92(5-6) 1275-1287 
Lewis, M. (2008) "It Takes CO2 to Contango" Deutsche Bank Report

Mandell, S. (2008) "Optimal mix of emissions taxes and cap-and-trade" Journal of Environmental Economics and Management 56 (2), pp. 131-140

Marklund, P. Samakovlis, E. (2007) "What is driving the EU burden-sharing agreement: Efficiency or equity?" Journal of Environmental Management Volume 85, Issue 2, Pages 317-329

McKinsey \& Company (2007) “Reducing U.S. Greenhouse Gas Emissions: How Much at What Cost?” U.S. Greenhouse Gas Abatement Mapping Initiative, Executive Report December 2007.

Newell, R. Pizer, W. (2003) "Regulating stock externalities under uncertainty" Journal of Environmental Economics and Management 45 (2 suppl) 416-432

Otto, V.M. Loschel, A. Reilly, J. (2008) "Directed technical change and differentiation of climate policy" Energy Economics 30 (6) 2855-2878

Pindyck, R. (1999) "The long-run evolution of energy prices" The Energy Journal 20 (2)

Pizer, W. 2002 "Combining price and quantity controls to mitigate global climate change" Journal of Public Economics 85, pp409-434.

Poyry (2008) “Compliance costs for meeting the 20\% renewable energy target in 2020" Report to UK Department of Business Enterprise and Regulatory Reform, March 2008 http://www.berr.gov.uk/files/file45238.pdf

Redpoint (2007) "Dynamics of GB Electricity Generation Investment" Report to DTI for Energy White Paper http://www.berr.gov.uk/files/file38972.pdf

Reedman, L., P. Graham, P. Coombes. (2006) “Using a real-options approach to model technology adoption under carbon price uncertainty: An application to the Australian electricity generation sector" Economic Record 82 64-73

Richels, R. G. Blanford, G.J. (2008) "The value of technological advance in decarbonising the U.S. economy" Energy Economics, 30 (6) 2930-2946

Roques, F.A., Nuttall, W.J., Newbery, D.M., de Neufville, R., Connors, S. (2006) “Nuclear power: A hedge against uncertain gas and carbon prices?” Energy Journal 27 (4), pp. 1-23

Rosendahl, K. E. (2004) "Cost-effective environmental policy: implications of induced technological change" Journal of Environmental Economics and Management 48 1099-1121

Rothwell, G. (2006) "A real options approach to evaluating new nuclear power plants" Energy Journal, Vol. 27 No. 1 p37

Seifert, J. Uhrig-Homburg, M. Wagner, M.W. (2008) "Dynamic Behavior of $\mathrm{CO}_{2}$ Spot Prices" Journal of Environmental Economics and Management, Vol. 56, No. 2, pp. 180-194

Sorrell, S., Sijm, J. (2003) "Carbon trading in the policy mix" Oxford Review of Economic Policy 19 (3), pp. $420-437$ 
Stankeviciute, L., Criqui, P. (2008) "Energy and climate policies to 2020: The impacts of the European "20/20/20" approach" International Journal of Energy Sector Management 2 (2), pp. 252-273

Stern, N. 2007. The Economics of Climate Change: The Stern Review. Cambridge, UK: Cambridge University Press

Weitzman, M.L. 1974 “Prices vs. Quantities” Review of Economic Studies 41 (4), 477-491

Yang, M., Blyth, W., Bradley, R., Bunn, D., Clarke, C., Wilson, T. (2008) "Evaluating the power investment options with uncertainty in climate policy" Energy Economics 30 (4), pp. 1933-1950 